\title{
Wireless mote based Explosive detection Land Rover using EC Sensor (WEDLRE)
}

\author{
V. Manasa, K. Raghava Rao \\ Department of Electronics and Computer Engineering, KL University, India
}

\begin{tabular}{l} 
Article Info \\
\hline Article history: \\
Received Apr 24, 2015 \\
Revised Jun 12, 2015 \\
Accepted Jun 29, 2015 \\
\hline Keyword: \\
EC Sensor \\
Explosive \& Explode Detection \\
GPS/ZigBee \\
Land Rover \\
Wireless Communication
\end{tabular}

Article Info

2,2015

Accepted Jun 29, 2015

\section{INTRODUCTION}

As we are in country where the attacks comes from the terrorist countries to affect countries wealth; there are many reasons to propose this system are spreading of terrorism in the world has alarmed across the globe to be reliable detection of the explosives to save life and wealth of country. [1] This tends to researchers to research on the explosives and explosive detection using various techniques and new methodology also invented for detection. To ensure a high security system to secure life of people and wealth a "Wireless Explosive detection Land Rover using EC Sensor" is proposed.

A WSN are of small nodes which can be more feasible to use, more sensitive to the sensing objects, computation, less weight. The sensors which are used on the nodes measures the exact conditions related to the situation around the sensors and converts to the electrical signal. Using of sensor networks there will be tremendous advantages which offer traditional centralized approaches. Some of them are efficiency in communication, tracking the target, efficient network and [2] power usage etc., some of the applications where the WSN will be used are environmental monitoring, and Industrial diagnostics, in medical field and in Battle field etc. One of the major pros of WSN is it can detect and track the static and movable objects.

\section{EXPLOSIVES AND ITS CLASSIFICATION}

Explosives are the combination of $\mathrm{N}_{2}$, carbon, $\mathrm{H}_{2}$ and $\mathrm{O}_{2}$ which forms an explosion. This results a sudden release of great heat and pressure. [3] These explosives have various burning rates based on the explosives are classified as below. Blasts in India from beginning stages to till now 57 occurred and 1870 
people are fatalities. Among all the explosives the RDX, HMT, TNB, TNT are majorly used by the attackers. The classification is shown in Figure 1.

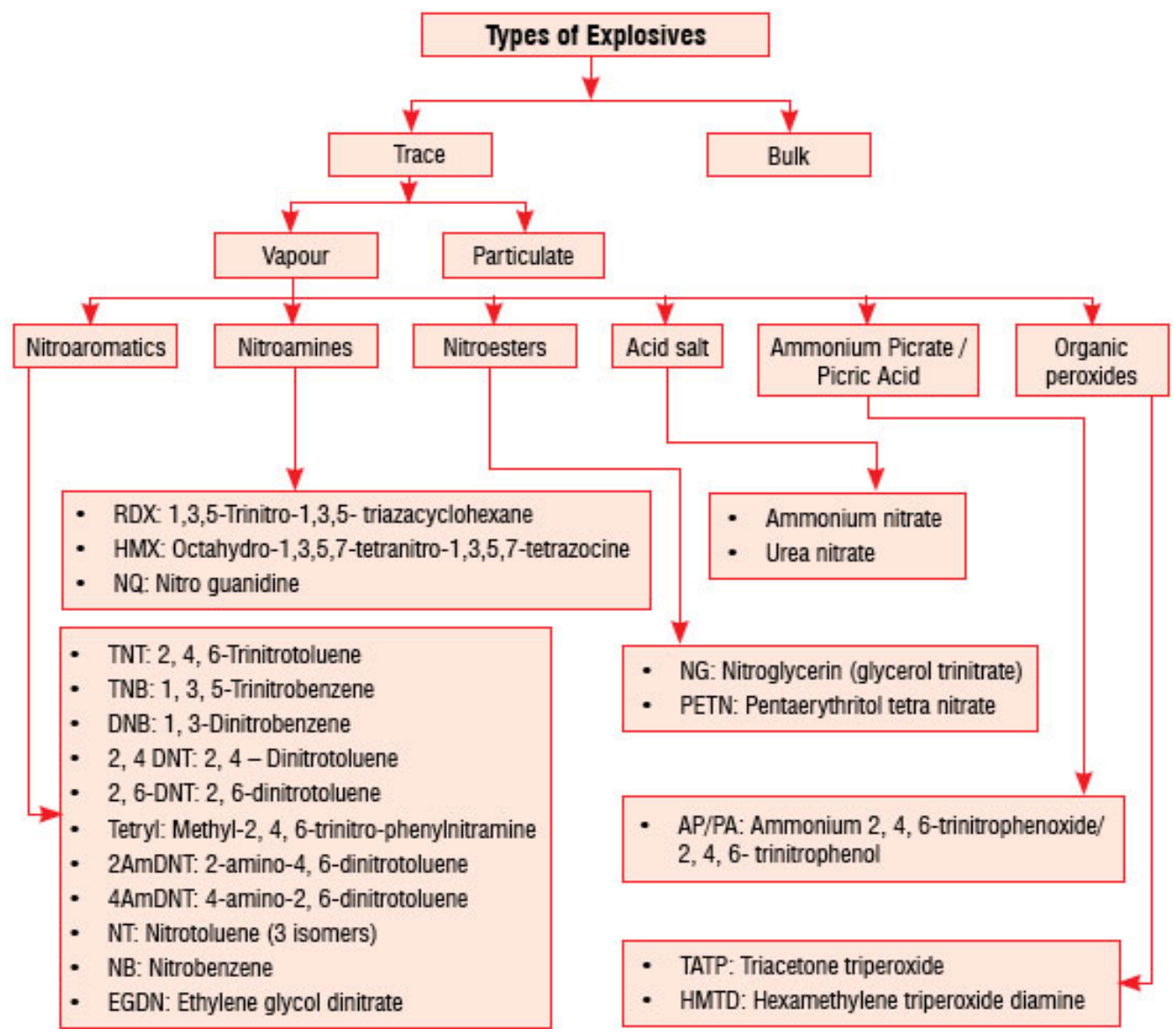

Figure 1. Classification of Explosives

Due to low volatility of explosives, polymers etc., so to monitor such elements they will accumulate the sensing elements of the detectors.

\section{DATA ANALYSIS AND CHARACTERIZATION OF EXPLOSIVES}

For the detection of the explosives we have various methodologies before defining this we have to know the characterization of explosives in various parameters like chemical, physical, acoustic, thermal, mechanical and Electromagnetic properties have to analyze. By detailed and successful analyzing of characteristics of explosives will help for detection of any type of explosives and can easily develop the sensing techniques [4], [5]

\subsection{Mechanical Analysis of Explosives}

This type of analysis of will also refer as Surface adhesion which will play a critical role in their detection of explosives. Beaudion et al. researched and found out the vdW forces by mitigating with the electrostatic and capillary which gives the effect of different military explosives like TNT, RDX, HMX etc., The measurement of this force will be performed using an Atomic force microscopy, [4], [5] AFM and simulated with the vdW force based adhesion model and composite effective Hamaker constant. From his studies we well knew that how the explosive reaction will be there on various surfaces like smooth or porous or hard surfaces. 


\subsection{Physical Analysis}

This type of analysis will also be referred as Surface morphology, to know the physical analysis of explosives gives a shocking and detonation properties. This brings a great interest among the researchers in developing explosives with insensitive properties for storage and transport purposes. Majority of work going on the RDX and PETN which are highly stable and crystalline high explosives. Some techniques are introduced to comprehend the mechanism of initiation and detonation come from the correlated to density, surface area, particle size and crystal morphology, AFM and scanning of electro microscopy (SEM). This morphology will play a crucial in detection of explosives the data of it will give the specifications of the life vapor, pressure, density etc. [6], [7]

\subsection{Acoustic Analysis}

Using this analysis we can determine the "Damage”.[8], [9] While transporting the explosives if anything then there will be huge damage and degradation. Thus it results for the evolution of new damage energetic materials such as SEM, AE (Acoustic Emission) will be used to evaluate the damage by PBXs. AE will be more helpful to revel the full field damage distribution on PBX and found DL band. By this band there is a good scope to find the non-linear behavior and structural evolution.

\section{METHODS FOR DETECTING OF EXPLOSIVES}

A number of great proceedings have been done on the individual modes of explosives detection. There to detect such type of explosives we have various methologies and to maintain high alert security in the mass areas like airports, theatres malls etc. Some of the detecting technics are Spectroscopic approaches, using Canines, Various Sensors, and QCM Method etc. For detecting the explosives we had many techniques like Spectroscopic techniques, Sensor techniques etc.,[10]

\subsection{Spectroscopic Approaches}

These types of approaches will show high sensitivities of explosive traces in minute quantity. Some of the techniques are Ion Mobility spectroscopy, Mass Spectroscopy, Terahertz Spectroscopy, IR Spectroscopy, LID spectroscopy etc.,

IMS (Ion Mobility Spectroscopy) [11], [12], [13] is one of the most important and widely used techniques which test the sample of explosives in qualitatively and quantitatively. The working of it well known as mobility of ions with the gases with the electric field. The sample vapors are ionized with the atmospheric pressure then the drift times are related to the mass of the ions by determining the mass ratio.

Mass Spectroscopy is the one of the detection method for explosive. It mainly used for the security and forensic analysis which would involve the substance of interest either being within a complex sample or absorbed upon a surface.[14], [15]

THz Spectroscopy [16] is the detection analysis of explosives, the waves will be penetrate through many non-polar dielectric materials. The range of $\mathrm{THz}$ will be 0.1 to $10 \mathrm{THz}$ radiation as a prospective sensor and imaging agent for the detection of the concealed explosive substance

IR Spectroscopy is that which samples and passed through an IR beam and absorbs at specific wavelength allowing detection of many particles. Sensitivity and specificity is the major drawback [17]

\section{CHEMICAL SENSOR TECHNOLOGIES}

This type of technology will be more useful for the exploring the explosives in our surrounding places with low cost, highly transferable, with more accurate information about the explorations. The main principle of the chemical sensor will be some immobilized active ions will recognize the explosive if it there. [18] After those recognition will be simplified more into other form to get in measurable content. For an instance, TNT is one of the highly used explosive which will be a compound mixing of $\mathrm{N}_{2}$ groups, when it reacts then we can see the color changes in it. The checmical structre of each explosive is shown below in figure 2 . 


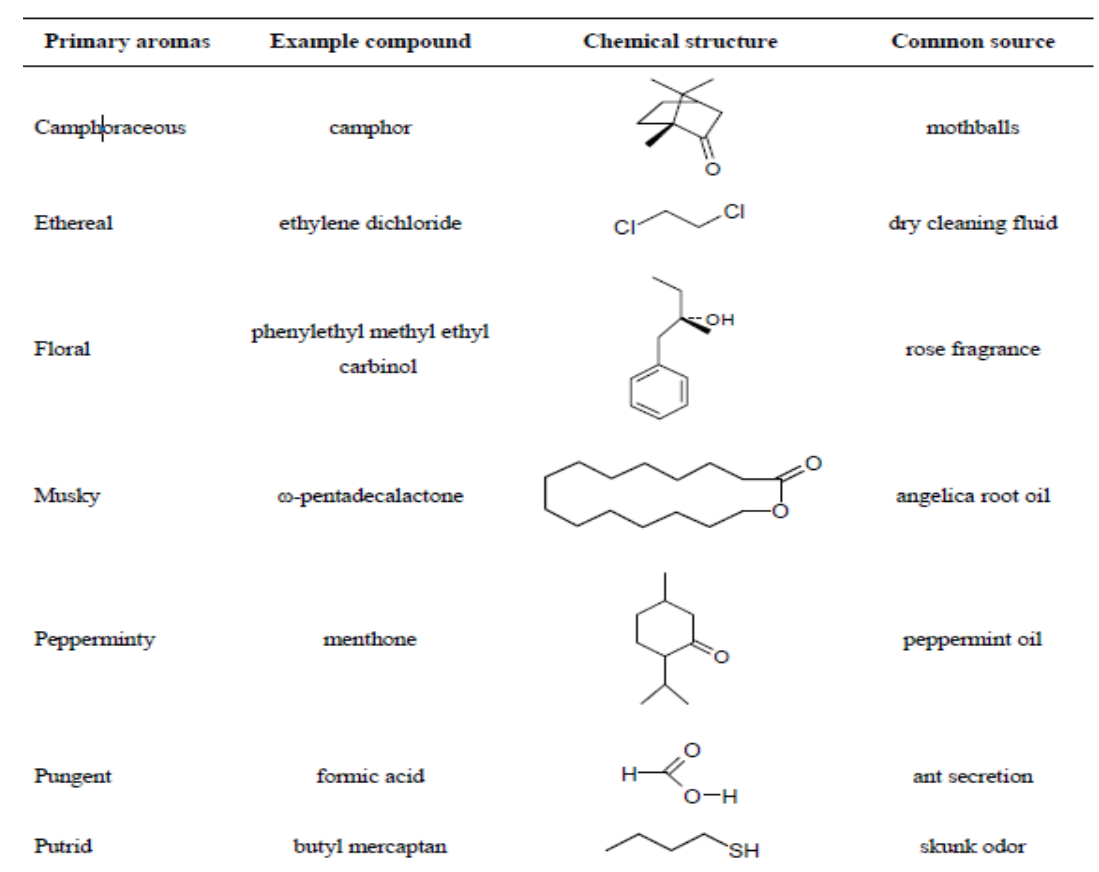

Figure 2. Structure of explosive chemicals

\subsection{Electro Chemical Sensor [EC Sensor]}

In these EC Sensor generally they are classified into various types. They are a) Potentiometric, b) Amperometric, c) Conductometric based on their approach capabilities. These sensor are very sensitive, inexpensible, with viable miniaturization [19], [20]. These sensor will have an approach of reacting with the chemical in REDOX operation mode. The figure shown in fig 3The output will be in electrical mode so due to the REDOX reactions with the nitro compounds they lend themselves to the Electro Chemical detection. In every EC sensor we have three major parts. [21] They are as follows

a. Gas Permeable membrane: This is used t cover the sensing electrode of the sensor, in some cases it will avoid the gas molecules to reaching the surface of the electrode.

b. Electrode: In the manufacturing of the EC sensor the selection of electrode id very important. It is a catalyzed material which will performs the half-cell reaction over its life time. Based on the design of the sensor the electrode which you use will be different.

c. Electrolyte: It is the fluid where the overall cell/sensor reaction will takes place through the electrodes effectively

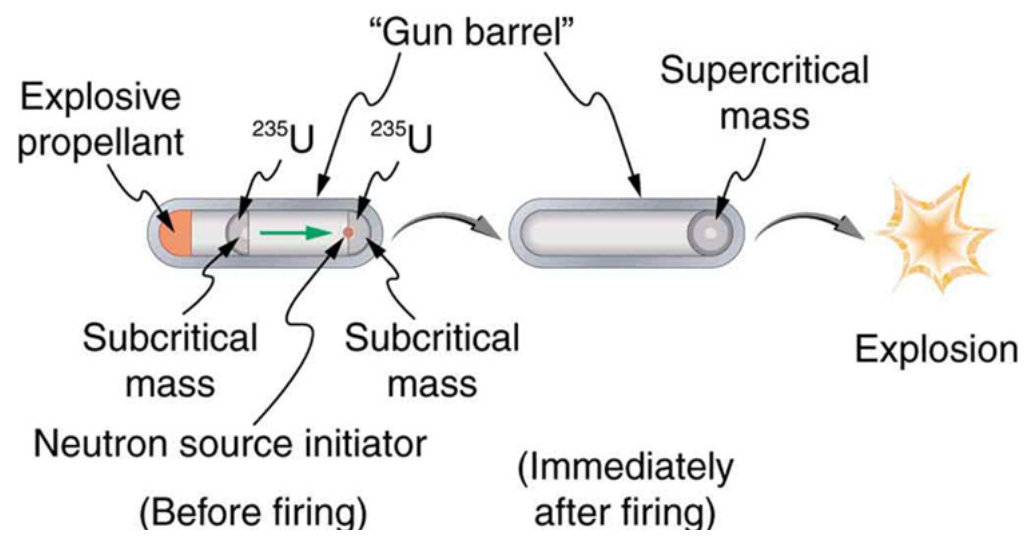

Figure 3. Explosive Analysis 


\section{DRAWBACKS IN THE EXISTING SYSTEM}

Presently using devices for the explosive detection will represents only one layer of defense. These devices will be operated by the well trained people, during the detection of explosive if it explode we can lose a good analyst. [21], [22]. Other than this we have other drawbacks also as below

a. Identifying the material in Ambiguity

b. The people won't have proper knowledge on explosives

c. To analyze the explosive it will take more time period

d. It won't have any decision making whether it is an explosive or other

\section{PROPOSED THEME FOR THE EXPLOSIVE DETECTION}

In the proposed theme we are mainly concentrate on the detection of explosives in less amount of time with low cost and power and with less manual power and manual error. The Exact Identification of the explosive can be easily defined. The system consists of Data Acquisition which will be maintained by the LAB VIEW. Here whole data can be maintained as a text file with the time basis. Risk comparison analysis can be shown in the below table 1 in tracking of the explosives

Table 1. Explosive dectection in various systems

\begin{tabular}{ccccc}
\hline Analyzer & Distraction & Creation of bomb & Arriving to spot & Life risk \\
\hline Sniffer Dog & More than 50\% & Can’t be detected & Slow & High \\
Human expert & Nearly 20\% & Can't be detected & Fast & High \\
Expert system & Less than 5\% & Can be detected & Already sensing & No \\
\hline
\end{tabular}

How the Tracking of explosives can be done is as follows. Most of the explosives will have low pressure, with room temperature. When the sensor sense the radiation of the explosives with the information will be noted through the LAB View analysis then this is will be compared with the values of pressure, temperature, vapor of chemicals. If any explosive will be detected then with in no time then through the GSM it will send the message to the nearby control room and the hospitals to save the people Then we can get whether any explosive found or not. The graphical analysis of explosive detection is shown below in figure 4.

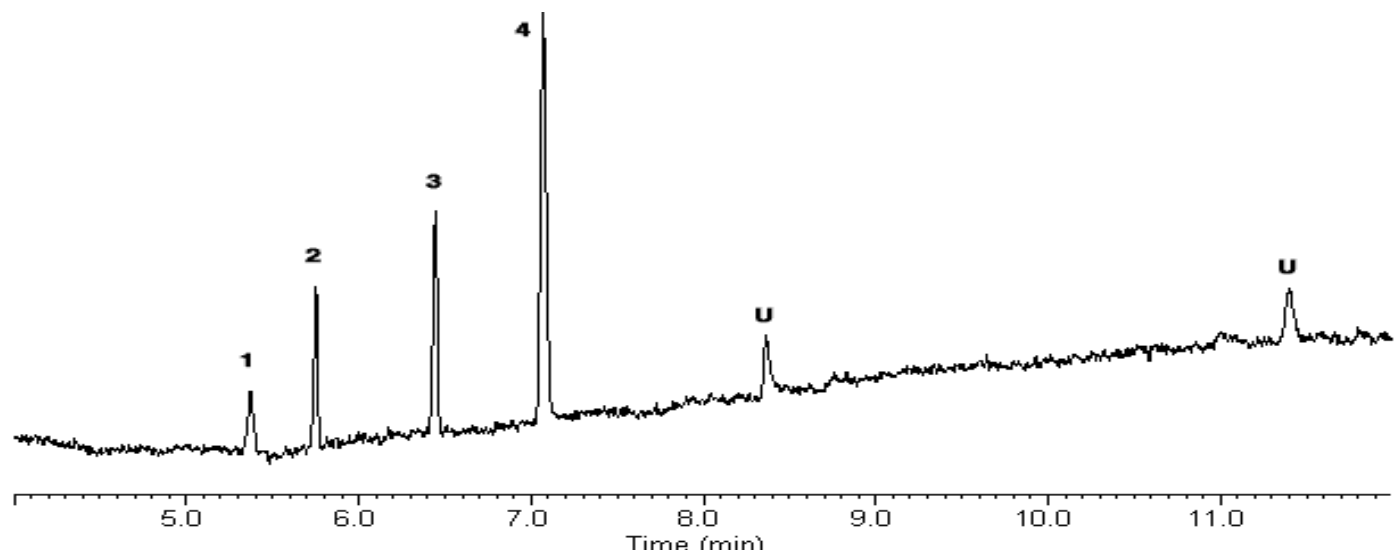

Figure 4. The graphical analysis of the explosive detection

\section{CONCLUSION}

From this paper clearly explained about the classification of the explosive materials and its characterization how they react with the other chemicals. How the wireless communication will be maintained from the sensors with the GPS. In this we clearly say about the clear detection of explosives with high accuracy, with low cost device. This device will more useful in the gathering places, like community halls, airport etc. If any explosive device detects then with in no time through the GSM a message will be sent to the nearby control room of the police, and nearby hospitals with the exact location values. By this we can easily trace the explosive can easily diffuse that explosive. This will be more useful to the people to save the life from various attacks. It is like a land rover. Future work will be continued with the consuming the power with the solar energy. 


\section{REFERENCES}

[1] Bruce Hoffman, "The Logic of Suicide Terrorism”, in Terrorism and Counterterrorism: Understanding the New Security Environment. McGraw Hill, 2004.

[2] E. Cayirci, et al., "Wireless sensor networks: a survey”, IEEE Computer, vol. 38, no. 4, pages 393-422. Mar 2002.

[3] “Nanosensors for Trace Explosive Detection” Larry Senesac, Thomas G. Thundat, 2007

[4] Zakon Y, Lemcoff NG, Marmur A, Zeiri Y (2012), Adhesion of Standard Explosive Particles to Model Surfaces. $J$ PhysChem C, 116: 22815-22822.

[5] Chaffee-Cipich MN, Sturtevant BD, Beaudoin SP (2013) Adhesion of explosives. Anal Chem 85: 5358-5366.

[6] Bouma RHB (2008), On the impact testing of cyclotrimethylene trinitramine crystals with different internal qualities. Journal of Applied Physics 103.

[7] Bellitto VJ, Melnik MI (2010) Surface defects and their role in the shock sensitivity of cyclotrimethylenetrinitramine. Applied Surface Science 256: 3478-3481

[8] Zhou ZB, Chen P, Huang F, Liu S (2011), Experimental study on the micromechanical behavior of a PBX simulant using SEM and digital image correlation method. Optics and Lasers in Engineering, 49: 366-370.

[9] Greenaway MW, Laity PR, Pelikan V (2005), X-ray Microtomography of Sugar and HMX Granular Beds Undergoing Compaction. AIP Conference Proceedings, 845: 1279-1282.

[10] I. Cotte-Rodríguez, H. Hernández-Soto, H. Chen, R.G. Cooks, In situ trace detection of peroxide explosives by desorption electrospray ionization and desorption atmospheric pressure chemical ionization, Anal. Chem. 80 (2008) 1512-1519

[11] R.G. Ewing, D.A. Atkinson, G.A. Eiceman, G.J. Ewing, A critical review of ion mobility spectrometry for the detection of explosives and explosive related compounds, Talanta. 54 (2001) 515-529

[12] M.J. Waltman, P. Dwivedi, H.H. Hill Jr., W.C. Blanchard, R.G. Ewing, Characterization of a distributed plasma ionization source (DPIS) for ion mobility spectrometry and mass spectrometry, Talanta. 77 (2008) 249-255.

[13] J. Yinon (Ed.), Counterterrorist Detection Techniques of Explosives, 1 ed., Elsevier, Oxford, UK, 2007

[14] J.M. Nilles, T.R. Connell, S.T. Stokes, H. Dupont Durst, Explosives detection using direct analysis in real time (DART) mass spectrometry, Propellants Explos Pyrotech. 35 (2010) 446-451.

[15] T. Lo, I.S. Gregory, C. Baker, P.F. Taday, W.R. Tribe, M.C. Kemp, The very far-infrared spectra of energetic materials and possible confusion materials using terahertz pulsed spectroscopy, Vib. Spectrosc. 42 (2006) 243248.

[16] O.M. Primera-Pedrozo, Y.M. Soto-Feliciano, L.C. Pacheco-Londoño, S.P. Hernández Rivera, Detection of high explosives using reflection absorption infrared spectroscopy with fiber coupled grazing angle probe/FTIR, Sens. Imaging. 10 (2009) 1-13.

[17] M.E. Koscho, R.H. Grubbs, N.S. Lewis, Properties of vapor detector arrays formed through plasticization of carbon black-organic polymer composites, Anal. Chem. 74 (2002) 1307.

[18] H. Wohltjen, R. Dessy, Surface acoustic wave probe for chemical analysis. I, Introduction and instrument description, Anal. Chem. 51 (1979) 1458.

[19] C.F. Bernasconi, Kinetic and spectral study of some reactions of 2, 4, 6-trinitrotoluene in basic solution. I. Deprotonation and Janovsky complex formation, J. Org. Chem. 36 (1971) 1671.

[20] http://www.intlsensor.com/pdf/electrochemical.pdf

[21] Prabhakaran. S, Sharon Rosy. S "Detecting and Spotting Bombs Using Wireless Sensors and Expert Systems"

[22] S. Singh, Sensors-An effective approach for the detection of explosives, Journal of Hazardous Materials,.

\section{BIOGRAPHIES OF AUTHORS}

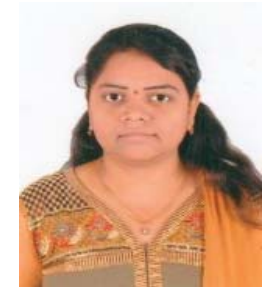

V. Manasa, M.Tech student of KL University in the Dept. of Electronics and Computer Engineering with the specialization of Wireless communications and Sensor Networks. I received B.Tech degree in 2009 in ECE. As I am very fascinate research in the Wireless Communications in routing nature of networks.

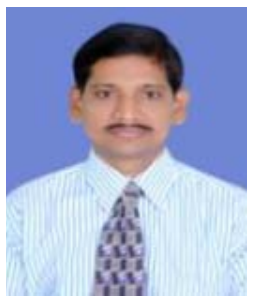

K. Raghava Rao, Professor in the Dept. of Electronics \& Computer Engg. He is having 15 years of experience in teaching for UG and PG engineering students and 3 years of Software Development experience in Singapore. He received B.E (CSE) from MG state University, M.Tech (CSE) from RVP University, Udaipur and Ph.D. (CSE) from Mahatma Gandhi University (Kasi Vidyapeeth), Varanasi, in the years 1995, 2005 and 2009 respectively. He published several papers in national \& international conferences and journals. He published 3 text books. Currently he is carrying a DST funded project in the area of Wireless sensor networks-sensor web enablement. His research interests are Wireless sensor networks, Embedded Sensor networks. He received a best paper award from DST Secretary and Best Teacher award from KL University He is also member of several technical organizations. 